\title{
Lucha del recuerdo sobre el más denso velo del olvido: profesor Gordiano Vite Ortega
}

\author{
The struggle of memory over the thickest veil of \\ oblivion: professor Gordiano Vite Ortega
}

\author{
Alejandro Moreno Lozano* \\ Aída Edna Amezcua Gutiérrez**
}

\begin{abstract}
* Investigador del Instituto de Estudios Superiores de Progreso de Obregón Hidalgo, México. Es Licenciado en Educación Especial, Maestro en Educación, Doctor en Ciencias de la Educación, director del Centro de Atención Múltiple No. 3 del estado de Hidalgo y Coordinador del Posgrado en Educación del Instituto de Estudios Superiores de Progreso de Obregón Hidalgo (IESPOH). Entre sus publicaciones recientes están "Madres de niños con discapacidad: viacrucis plagado de sinsabores" y "Adecuaciones para la enseñanza de la Historia: Discapacidad, discapacidad múltiple y Trastornos Generalizados de Desarrollo. Correo electrónico: amlcam@hotmail.com

(D) https://orcid.org/0000-0003-0419-0182

** Investigadora del Instituto de Estudios Superiores de Progreso de Obregón Hidalgo, México. Licenciada en Derecho por la Universidad Nacional Autónoma de México (UNAM), así como Maestra en Educación y Doctora en Educación por el Instituto de Estudios Superiores de Progreso de Obregón Hidalgo (IESPOH). Entre sus publicaciones más recientes están "Madres de niños con discapacidad: viacrucis plagado de sinsabores" y "Niños que trabajan en México ¿Y su derecho a jugar?" Correo electrónico: aidaag0428@gmail.com

(D) https://orcid.org/000-0003-4784-24-86
\end{abstract}

Historial editorial

Recibido: 06-junio-2020

Aceptado: 10-noviembre-2020

Publicado: 29-enero-2020

ISSN-e: 2594-2956 


\section{Lucha del recuerdo sobre el más denso velo del olvido: profesor Gordiano Vite Ortega}

\section{Resumen}

La finitud de los seres humanos es lo que hace interesante la escritura y el reconocimiento de la complejidad y la contradicción en su interacción en el mundo social es la constante aparente que los caracteriza, convirtiéndose en los dos elementos fundamentales de la investigación que comienza en 2014 y se extiende hasta 2020 , con el objetivo imperante de interpretar, por medio del análisis hermenéutico del discurso, la vida dentro de la institución escolar de los profesores con 50 años o más de servicio dentro de la Secretaría de Educación Pública del Estado de Hidalgo (SEPH). En ese trayecto se lograron dos entrevistas con el profesor Gordiano Vite Ortega sobre las que gira el escrito. Estos relatos se habían quedado en la mera transcripción, hasta que por des fortuna de su muerte, ocurrida el 27 de enero de 2018, apuró el tratamiento analítico desde una perspectiva cualitativa, por considerarse la más acertada en el tratamiento de los fenómenos de tipo social, como son la vida y obra educativa de este personaje. Los resultados que aquí se muestran, se centran en los relatos de vida que se rescatan por medio de la técnica de la historia oral, en tanto que se reconoce que los investigadores "somos la fuente que tenemos delante $y$ la conocemos personalmente" (Portelli, 20I6, p. 34). El rescate del discurso se logró por medio de la técnica de entrevistas a profundidad, para rescatar sus experiencias de 1949 a 1956 en dos vertientes: a) como estudiante de secundaria y normalista en el espacio arquitectónico de la ex hacienda denominada El Mexe donde se ubicó geográficamente la Normal Rural "Luis Villarreal" y, b) su incorporación al magisterio hidalguense desde 1956 hasta su muerte en el mes de enero de 2018. Se trató de seguir la metodología de un relato de vida con la directriz de relatos triangulados, siendo el punto de trípode el life history, pero complementado con los testimonios de otras personas, fuentes documentales, transcripciones $o$ archivos relacionados con la vida en cuestión.

Palabras Clave: Autoridad educativa, estudiantes, Normalismo rural.
The struggle of memory over the thickest veil of oblivion: professor Gordiano Vite Ortega

\section{Abstract}

The finiteness of human beings is what makes writing about them interesting, and the recognition of the complexity and contradiction in their interaction in the social world is the apparent constant that characterizes them. These are the two fundamental elements of the research that began in 2014 and extended until 2020, with the prevailing objective of interpreting, through the hermeneutical analysis of discourse, the life within the school institution of the professors with 50 years or more of service within the Ministry of Public Education of the State of Hidalgo (SEPH). During that research journey, it was possible to get two interviews with professor Gordiano Vite Ortega, on whom this paper revolves, which had been only transcribed until, unfortunately, his death on January 27,2018 , when they were analyzed from a qualitative perspective, as it was considered the most accurate in the treatment of social phenomena such as his life and educational work. The findings shown here focus on the life stories that emerged from the oral history approach while recognizing that the researchers "are the source before us and we know it personally". (Portelli, 20I6, p. 34). The stories were obtained through in-depth interviews and tell his experiences from 1949 to I956 in two aspects: a) as a secondary school student and a normalista in the architectural space of the former hacienda called el Mexe, where the Normal Rural "Luis Villarreal" was located, and b) his incorporation into the Hidalgo teaching profession from 1956 until his death in January 2018. The narrative story methodology with triangulated stories was followed, being the life story the tripod point, but complemented with the testimonies of other people, documentary sources, transcripts, and files related to the life of Prof. Vite Ortega. The whole process is framed from a qualitative perspective as it is considered suitable for dealing with social phenomena.

Keywords: Educational authority, students, rural Normalism. 
Lutte du souvenir sur le voile le plus dense de l'oubli: Professeur Gordiano Vite Ortega

\section{Résumé:}

La finitude des êtres humains est ce qui rend intéressant l'écriture et la reconnaissance de la complexité et la contradiction dans leur interaction dans le monde social est la constante apparente qui les caractérise, devenant les deux éléments fondamentaux de la recherche qui commence en 2014 et s'étend jusqu'en 2020 , l'objectif dominant étant d'interpréter au moyen de l'analyse herméneutique du discours, la vie au sein de l'établissement scolaire des enseignants ayant au moins 50 ans de service au sein du Secrétariat d'Etat à l'Education Publique de l'Etat d'Hidalgo (SEPH). Au cours de ce voyage, deux entretiens ont été obtenus avec le professeur Gordiano Vite Ortega, sur lequel tourne le texte, qui étaient d'abord restés dans la simple transcription jusqu'à ce que heureusement sa mort, le 27 janvier 20I8, ait précipité le traitement analytique d'un point de vue qualitatif en le considérant comme le plus approprié dans le traitement des phénomènes de type social comme sa vie et œuvre éducative. Les résultats présentés ici se concentrent sur les récits de vie qui sont sauvés par la technique de l'histoire orale alors qu'il est reconnu que les chercheurs "sont la source devant nous et nous la connaissons personnellement" (Portelli, 2016, p. 34). Le sauvetage du discours a été réalisé par la technique des entretiens approfondis pour sauver ses expériences de 1949 à 1956 dans deux volets : a) en tant qu'étudiant de secondaire et normaliste dans l'espace architectural de l'ancienne hacienda appelée le Mexe où la Normale Rurale "Luis Villarreal" a été géographiquement située et, b) en tant qu'enseignant ayant été intégré dans le corps enseignant de 1956 à sa mort en janvier 20I8. On a essayé de suivre la méthodologie d'un récit de vie avec la directive des récits triangulaires étant le point de trépied le life history, mais complété par les témoignages d'autres personnes, sources documentaires, transcriptions ou archives liées à la vie en question. Toute la démarche s'inscrit dans une perspective qualitative considérée comme apte à traiter les phénomènes sociaux.

Mots-clés: Autorité éducative, Étudiants, Normalisme rural.
Walka o pamięć, przeciw zapomnieniu: profesor Gordian Vite Ortega

\section{Streszczenie:}

Natura ludzka jest tym, co sprawia, że pisanie jest interesujące, a uznanie złożoności i sprzeczności w interakcji w świecie społecznym jest widoczną stałą, która ja charakteryzuje. Jednoczesnie stając się podstawowym elementem badań, które rozpoczynają się w $2014 \mathrm{r}$. i trwają do 2020 r., ktorych celem jest hermeneuteczna analizę dyskursu: życie nauczycieli z 50 lat lub więcej służby w Sekretariacie Edukacji Publicznej stanu Hidalgo (SEPH). Udalo sie przeprowadzic dwa wywiady $\mathrm{z}$ profesorem Gordiano Vite Ortega, które udalo sie opublikowac juz po jego smierci 27 stycznia 2018 r., analizujace jego dzialalnosc spoleczna i zycie. Wyniki analiz koncentrują się na historiach z zycia wzietych, które udalo sie zrekolpilowac dzieki uzyciu metod stosowanych historii ustnej, ponieważ uznaje się, że naukowcy "są źródłem przed nami i znają je osobiście" (Portelli [2016], str. 34). Zastosowano miedzy innymi technikę pogłębionych wywiadów, ktora odniosla sie do jego doświadczen z lat 1949-1956: a) jako licealista i normalista $\mathrm{w}$ przestrzeni architektonicznej dawnej hacjendy zwanej Mexe, gdzie znajdowala sie szkola wiejska imienia "Luis Villarreal" , b) włączenie profesora do Magisterium Hidalguense od 1956 do jego śmierci w styczniu 2018 roku. To było zgodne z metodologią historii życia gdzie historia jednostki jest uzupełniona przez świadectwa innych osob, źródeł, dokumentów, transkrypcji lub plików związanych z danym życiem. Całość przebiega $\mathrm{w}$ perspektywie jakościowej jako idealnej do radzenia sobie ze zjawiskami społecznymi.

Słowa kluczowe: Kurator oświaty, uczniowie, szkolnictwo wiejskie. 


\section{Marco teórico}

La teoría que da norte a esta investigación, retoma los postulados de algunos pensadores de los hechos sociales que permiten distinguir en la vida del profesor Gordiano Vite Ortega, algunas pautas de acción humana mientras transcurría su vida en las complejas arenas sociales de la educación, donde se desenvolvió por 62 años como profesor, director y supervisor escolar. En este transcurso

[...] lo biológico se refleja en lo político; el hecho de vivir ya no es un basamento inaccesible que sólo emerge de tiempo en tiempo en el azar de su muerte y su fatalidad; pasa en parte al campo de control del saber y de la intervención del poder (Foucault, 2007, p. 172).

En el paso biológico por las instituciones, el tiempo personal del sujeto, pasa por adherirse a las lógicas propias de los distintos puestos que le tocó desempeñar, haciendo uso del poder que le ceñía la institución y el que supo negociar con sus superiores y subalternos durante su intervención. La noción teórica de poder acuñada por Foucault, es de extrema utilidad en la investigación, como algo que circula y que no precisamente se posa sobre una persona, pero que sí es una relación de fuerza asimétrica entre el que la sufre y el que la ejerce.

Contamos, en primer lugar, con la afirmación de que el poder no se da, ni se intercambia, ni se retoma, sino que se ejerce y sólo existe en un acto. Contamos igualmente con otra afirmación: La de que el poder no es, en primer término, mantenimiento y prórroga de las relaciones económicas, sino prioritariamente una relación de fuerzas en sí mismo (Foucault, 2000, p. 27).

46 A través de este concepto se pueden mirar, las múltiples relaciones donde el profesor se constituye regularmente sobre quien ejerce el poder, mientras que el Estado es quien lo detenta y lo imparte.

El poder es algo que circula, que siempre está en movimiento, nunca se establece en un solo lugar, nunca está en manos exclusivas de 
alguien y tampoco se puede detentar de una vez y para siempre como un bien que se posee.

El poder funciona. El poder se ejerce sobre los individuos que siempre están en situación de sufrirlo y también de ejercerlo. Nunca son el blanco inerte o consciente del poder, siempre son sus relevos. En otras palabras, el poder siempre está en tránsito entre los individuos (Foucault, 2000, p. 38).

En esta relación siempre asimétrica entre los que tienen la facultad de ejercer el poder y los que están en posición de sufrirlo se dan procesos de resistencia ya "Que donde hay poder hay resistencias y no obstante (o mejor: por lo mismo), este nunca está en posición de exterioridad respecto del poder" (Foucault, 2007, p. II6). "Suele decirse que la información es poder, y brindarle o retenerlo, se convierte en un elemento importante [...]" (Fukuyama, I999, p. 264). La obtención de las ganancias podría ubicarse en el terreno de lo simbólico, con el reconocimiento de ser leal a ese que se la pide o también pueden ubicarse la ganancia más en el terreno de lo económico. La mezcolanza de las ganancias puede admitir ambas manifestaciones y también entender el puesto al que se arribe en el futuro.

El pasado, se concibe en esta investigación como un ente que ejerce fuerza vinculante con el sujeto que conforma la primera generación de Educación Especial en el estado de Hidalgo, y que en ese tenor se convierte en un pasado doble sentido: "Lo pasado pertenece irremisiblemente al tiempo anterior, perteneció a los sucesos de entonces, y puede a pesar de ello ser ahora" (Heidegger, I95I, p. 409). A los ojos analíticos de los investigadores de hechos históricos vigentes, que por su eficacia trastocan el presente por su influencia notable que se presentifica en la realidad de la generación en cuestión, y que se rescata anudando el bosquejo documental y -de manera puntual- la memoria de los implicados: "La historia se construye sobre jirones de la memoria. Existen lagunas porque ciertos elementos del pasado han dejado huellas menos duraderas que otros" (Duby, 1998, p. 28). 


\section{Resultados}

Estudiante de secundaria y normalista en la Normal Rural "Luis Villarreal" el Mexe Hidalgo

El profesor Gordiano Vite Ortega nació el Io de mayo de I935, originario de Calnali, enclavado en la Huasteca de uno de los 84 municipio que conforman el estado de Hidalgo. La distancia actual por carretera es de 222 kilómetros hacia el municipio de Francisco I. Madero, donde se ubica la escuela Normal Rural "Luis Villarreal", institución que le acogió por 7 años, como estudiante. Actualmente la distancia se recorre en un tiempo aproximada de 5 horas. En I949 el tiempo casi se triplicaba por las condiciones del poco desarrollo de las vías de comunicación, que se hacía la más de veces por terracería y veredas, donde los automotores a gasolina o diésel no podían circular.

En el año citado, el tiempo aproximado era de 23 horas de Calnali hasta el Mexe. La primera parte del recorrido se hacía a caballo hasta un poblado que lleva por nombre Ixtlahuaco, perteneciente al municipio de Lolotla. De ahí existía la posibilidad de abordar el transporte que en ese tiempo pertenecía a la empresa denominada Autobuses de la sierra ${ }^{\mathrm{I}}$ que llegaba hasta a la ciudad de Pachuca y de ahí era necesario tomar otro hasta Tepatepec, hoy Francisco I. Madero, donde se encuentra geográficamente la ex hacienda de $E l$ Mexe, Hidalgo.

Justo en el año de 1949, a la ex hacienda del Mexe, llega el profesor, cuando a nivel nacional las cosas no favorecían al normalismo rural en el régimen de Manuel Ávila Camacho. Con este presidente ocurre el rompimiento del pacto entre el normalismo rural y el Estado, ya que se centró en recomponer el pacto con los terratenientes afectados por el gobierno del expresidente Lázaro Cárdenas, con su llamada Reforma Agraria, en la que repartió i8 millones de hectáreas entre más de 5 I mil 400 campesinos. 
En ese tiempo se construyó desde el poder una "leyenda negra" a partir de que una veintena de ellas se fue a huelga demandando mejor alimentación, reconstrucción de sus edificios escolares y dotación de material de estudios. Desde ese momento estas instituciones comenzaron a recibir acusaciones de ser semilleros de comunistas (Rojas, 2017, p. 12).

A su llegada al plantel, el profesor Gordiano se enfrenta con un primera infortunio al no alcanzar cupo para inscribirse al primer año de educación secundaria. Bajo esas condiciones, toma postura y prefiere volver a inscribirse al sexto año, a pesar de contar con el certificado de educación primaria concluida. En esa dinámica se lleva a cabo la espera ${ }^{2}$ del siguiente ciclo, para quedar inscrito oficialmente como alumno de la entonces Escuela Regional Campesina bajo la administración de la Secretaría de Educación Pública (SEP), en un espacio histórico que venía albergando desde el I5 de noviembre de 1926 ${ }^{3}$ a la Escuela Central Agrícola del Estado de Hidalgo (Cortés y Hernández, 2009), a raíz de su inauguración por el entonces presidente Francisco Plutarco Elías Campuzano, ${ }^{4}$ mejor conocido como Plutarco Elías Calles. Años después reorientaron su función para formar entre sus muros a los profesores que se desempeñarían más adelante en las comunidades rurales del estado de Hidalgo y de la República Mexicana.

La historia de las escuelas Normales presenta cambios importantes para la carrera normalista, que asumen los formadores ante las disposiciones oficiales, en el contexto de relaciones, los conflictos y los procesos culturales, las políticas de acuerdo a los proyectos de educación nacionalista, rural, socialista, unidad nacional, descentralización, modernización, que aseguraran la continuidad de la institución. Las escuelas Normales constituían centros abiertos a la discusión positiva de los problemas inherentes a la transformación, superando así el hermetismo, el aislamiento y la insensibilidad frente a la realidad y a la urgencia de consolidar en cada país la unidad nacional.

Los formadores interpretaban y daban sentido a la aplicación de las disposiciones normativas, no es que las modificaran, sino que las 
adaptaban a lo que pensaban, les permitía rescatar la dimensión social de la formación y los retos del normalismo en ese momento. El carácter diverso, dinámico y cambiante de su origen de formación, los procesos de incorporación o contratación, el tiempo dedicado a la institución, el tipo y compromiso de participación, las relaciones con el gremio de formadores, y en la comunidad en general, dan cuenta de la heterogeneidad de los formadores que trabajaban en las Normales rurales.

El concepto formadores se entiende como una configuración que aparece en un momento histórico determinado, con prácticas culturales específicas que definen tensos equilibrios para dar orientación a la actividad que caracterizaba a los planteles. Los formadores son artífices de un hacer y saber docente. La Normal Rural "Luis Villarreal" del Mexe, Hidalgo desarrolla de forma distinta su quehacer educativo, que resignifica a partir de los planes de estudio estandarizado en la República Mexicana. En todas ellas se reflejan los problemas políticos, económicos y sociales del país que modifican las políticas educativas de acuerdo a los intereses e ideologías gubernamentales. En este sentido, el participar en la construcción de su quehacer y en el hacer escuelas, el formador de la Escuela Normal Rural está inmerso en un proceso que implica una gran cantidad de aprendizajes para su desempeño, además, se va involucrando en un proceso de apropiación de saberes y prácticas que le permiten interpretar, adecuar y replantear su participación en la caracterización de la institución escolar y en la configuración de hacer escuela. Es desde esta perspectiva que toma sentido el papel histórico y dinámico del formador en su papel de propiciador de los procesos de formación, como a las experiencias o acciones que son diseñadas a propósito del ejercicio potenciador de las prácticas y los discursos propios de la Escuela Normal Rural.

El ingreso a la Normal, implicaba lógicas muy particulares a las que el profesor Gordiano se vio en la necesidad de construir sobre la nueva realidad que, dicho sea de paso, no le era totalmente ajena, puesto que su hermano inscrito en ese momento en primer año de educación Normal, contaba anécdotas e historias sobre la vida dentro 
del internado, las cuales escuchaba con atención, con lo que realizó una interpretación de ese mundo que parecía distante a su experiencia, hasta que por fin pudo imbuirse de esa realidad particular que dejó impregnada su memoria y marcó el derrotero que su vida tomaría al entrar a la etapa adulta.

Una de las primeras experiencias fue enfrentarse a una práctica estudiantil que se denominaba como "bienvenida" que se caracterizaba por el corte de pelo realizado por sus compañeros de grados superiores. Desde ese momento marcaba simbólicamente un rito de iniciación del que se conocía con el sobrenombre genérico de "Chaiva(s)". El término se emplea en los discursos recientes de profesores del mismo espacio físico de la primera generación de educación especial (1995-1999), el cual ha sufrido un acomodo a "Chivo(s)". El sentido hace alusión al que viene del campo y huele a sudor (Moreno, 2018). Dicha actividad no distinguía entre los que se encontraban bien posicionados por medio de las relaciones sociales, de tal modo que tampoco excluyó al profesor Gordiano, aunque contaba con su hermano en grados superiores. Tal acto es puesto como natural, obviando su carácter social y de violencia de poder por imponer la supremacía de los que saben cómo y de qué forma funcionan las cosas en el entendido foucaultiano, en la vertiente de que el poder se ejerce y sólo existe en el acto (Foucault, 2000).

Como es natural una costumbre de la escuela era que todos los que llegábamos de nuevo ingreso pues lo primero era que nos tenían que trasquilar y pues nadie a pesar de que mi hermano tenía ya amigos ahí relacionados... relacionado con todos ellos eh... quiso intervenir para que no me trasquilaran, pero era una tradición, no había manera de evitarlo y que fue mi primera experiencia ahí en la Escuela Normal, luego nos aventaron a la alberca pues tradiciones de la escuela (Vite, 20I4, p. I).

La tradición como forma de hacer las cosas, se repitió con algunas contadas excepciones, cuando las condiciones específicas de cada ciclo escolar lo permitían. En esa tónica, las circunstancias si bien se guardaban con regularidad reconocible, tomaban características que 
sorprendieron a los propios, como el hecho de que el respeto a la autoridad fuese la tónica y que en determinado momento infringieron la norma para mostrar la voluntad de los estudiantes.

Un primer hecho narrado de la memoria del profesor se da, cuando usando su habilidad como orador y su conocimiento profundo de las precariedades de salud y alimentación del internado, expuso ante las autoridades las cosas que a sus ojos debían mejorar, en medio de una reunión a la que asistieron también padres de familia de los alumnos internos:

Eh... y yo me atreví a pedir la palabra para hacer unos planteamientos en relación con las necesidades con las carencias que teníamos en la Escuela Normal, principalmente en alimentación, en vestuario y esas cosas. Esta situación pues como que no les pareció muy bien a las autoridades (Vite, 20I4, p. 2).

El discurso que emana del profesor en ese tiempo, es una toma de iniciativa fundamentada: "El discurso como acontecimiento es una forma más dialéctica a fin de tomar en cuenta la relación que conforma el discurso como tal, la relación entre acontecimiento y significado" (Ricoeur, I986, p. 23). Atreverse a tomar la palabra tuvo implicaciones que circularon más por la amenaza de su expulsión, lo que le preocupó en extremo y supo llevar con su espíritu revolucionario, sin que eso implicaría la ausencia de miedo como un mecanismo de profundas manifestaciones psíquicas y que ha acompañado a la humanidad a lo largo de una historia llena de fantasmas del pasado, sombras de incertidumbre e ignorancia frente a una amenaza.

La edad juvenil del profesor, se sincronizaba con las pintas de bardas

52 a modo de protesta social que se leían en cada recoveco de la escuela. Una de ellas escrita en la pared del pórtico principal de la Normal del Mexe, en color marrón se lee: "Ser joven y no ser revolucionario es una contradicción genética". Bajo este esquema se dirigió a las autoridades escolares más altas del estado de Hidalgo, a la Dirección 
de Escuelas Normales con el entonces profesor Guadalupe Nájera, quien le atendió después de su insistencia:

Ya fui con don Lupe y le dije oiga hay esta situación: mi intervención fue totalmente justa y normal en atención a los problemas que estamos viviendo en la... en la escuela, (me contestó) "no te preocupes" y ya me regresé y jvida normal! (Vite, 20I4, p. 3).

Levantar la voz indica un empoderamiento del profesor a través del lenguaje característico de lo específicamente humano (Voloshinov, 1976). El uso de la voz no era generalizado en el sentido de externar en público la forma en que lograban construir el mundo y menos conseguir por medio de su uso que las voluntades de quienes escuchan se sincronicen con el suyo. Aquellos que se atrevieron a tomar la voz en las reuniones en el auditorio emblemático a nivel local "Carlos Marx", de la Normal Rural, podían empatarse del sentido de su discurso revolucionario. "Cuando un sujeto se dirige a otro, presupone y necesita no dudarlo, que comparte con él ciertos códigos" (Rizo, 2009, p. 355).

El segundo suceso, donde se manifestó la voluntad de los estudiantes, tuvo una relación directa también con el uso que hace de la palabra, la cual afecta su relación de estudiante con el directivo en turno de la Escuela Normal, el profesor Manuel R. Serratos (Cortés y Hernández, 2009), quien anteriormente le había facilitado el transporte para que se atendiera debidamente una afectación que sentía en los ojos.

La distinción positiva que recibió de la dirección no fue bien recibida por sus compañeros y cuando los estudiantes que por ese tiempo ya se encontraban empoderados, desconocieron al profesor Serratos como directivo, se le encarga al profesor Gordiano Vite para que públicamente leyera un discurso donde hiciera del conocimiento de toda la base estudiantil, académica y de apoyo, la postura de la base estudiantil. Jugar con las condiciones que le requerían tomar la mejor postura fue una fortaleza del profesor, sin que necesariamente su ser moral saliera bien librado, puesto que la lectura le causó una gran incomodidad: 
Que me comisionan para pronunciar el discurso de desconocimiento (risas). Que fuerte. Y ahí en la fachada está... un, una como tribunita... escalera, ahí me tuve que pronunciar mi discurso, decirle que era indeseable que ya no lo queríamos en el Mexe. Sentí feo, pero si no lo hago me... híjole no sé qué hubieran hecho conmigo los estudiantes [...] finalmente se tuvo que ir pues sí le digo ya no encajaba ya (Vite, 20I4, p. 4).

La acción se enmarca en la fidelidad a su camaradería con las redes de amigos que había logrado construir "Los miembros de este tipo de red comparten reglas de reciprocidad" (Fukuyama, 1999, p. 264). No se niega la ausencia o presencia de una u otra manifestación de la amplia gama de los comportamientos humanos, con independencia de las instituciones que se pueblen. El profesor reconocía la implicación que apareja la condición del intercambio de favores que incluye su precepto no dicho, pero altamente eficiente que quien recibe está obligado a devolver el favor otorgado. "Se podría sentir la tentación de afirmar que la verdad objetiva del intercambio de obsequios es, en un sentido: kommon knowledge; sé que sabes que, cuando te doy sé que me devolverás" (Bourdieu, I994, p. I66).

Sin embargo, también existe la posibilidad de la no retribución al gesto de beneficio, tal como sucede. Esta acción se enfoca en que la maldad o la bondad son desde un punto de vista incremental o gradual, algo de lo que todos somos capaces en función de las circunstancias (Zimbardo, 2007) y que la perversión como una desviación de la normalidad está siempre presente en la especie humana y que ha sido bien representada en la literatura por sujetos reales:

¿Qué haríamos si Sade, Mishima, Jean Genet, Pasolini, Hitchkok y ¿tantos otros que nos legaron las obras más refinadas que quepa imaginar? Aquellos que aceptaron traducir para nosotros mediante sus extraños actos las tendencias inconfesables que nos habitan y reprimimos (Roudinesco, 2007, p. I5).

Su desempeño por su habilidad en el manejo magistral del discurso hizo que dentro de la organización estudiantil ocupara dos cargos, 
que le distinguieron en la Escuela Normal en las siguientes carteras: "Comité Ejecutivo de la de la Escuela Normal. Este... fui eh.. Secretario de Acción Juvenil, luego fui Secretario Coordinador de acción social" (Vite, 20I4, p. 8). Su dinamismo le llevó a organizar encuentros con escuelas de mujeres que formaban parte de la Federación de Estudiantes Campesino Socialistas de México (FECSM), fundada en 1935 bajo el cobijo del gobierno Lázaro Cárdenas del Río, presidente de México de I934 a I940.

El gobierno del General Lázaro Cárdenas, provenía de una revolución popular, la justicia social figuraba como referencia obligada en el discurso del nuevo régimen. Pero quizás en ningún otro ámbito eran más evidentes estos principios como en el sistema educativo, que adopta un análisis de lucha de clases. En él se proponía integrar a los sectores históricamente excluidos y ligaba el sistema educativo al desarrollo comunitario.

En este marco, la política educativa impulsada durante la administración cardenista tuvo un carácter profundamente reformador al pretender una transformación de las ideas, los fines, los modelos y las prácticas pedagógicas mediante el diseño y el impulso de la política educativa que se sintetizó y definió como educación socialista (Martínez, 2015, p. 29).

La orientación socialista que tuvo en la década de los treinta la educación mexicana, permaneció con fuerza en la Normal Rural "Luis Villarreal". Aunque su significado fue siempre ambiguo, mientras que para unos esta orientación significaba socializar los medios de producción, para otros representaba simplemente una lucha contra el alcoholismo, la superstición y el "fanatismo religioso". Con su "socialismo a la mexicana", el presidente Lázaro Cárdenas desde su campaña presidencial había delimitado el perfil del maestro de la educación socialista ${ }^{5}$ donde se concibe al maestro como revolucionario, líder social, consejero, orientador, que no sólo se aboca a enseñar a leer y a escribir, sino muestra también al proletariado la manera de convivir mejor, de crear una existencia más humana y más justa. Bajo este cobijo 
Organizados en la FECSM, los estudiantes campesinos lograron el derecho a opinar y decidir en el gobierno de sus escuelas, así como la autorización para tratar los asuntos relacionados con sus instituciones como un corporativo estudiantil ante las autoridades de la SEP (López, 2018, p. 77).

La Normal, se distinguía de las demás escuelas de su tipo en su fuerza política dentro del estado de Hidalgo y también dentro de la Federación, encabezando con éxito la secretaría en dicho organismo y las mesas de debate en los congresos políticos que organizaba y que tenían como característica peculiar que se celebraban donde hubiera las mejores condiciones, siendo la propia Normal Rural "Luis Villarreal". Esa condición histórica la adquiere desde el Segundo Congreso de la Federación de Estudiantes Socialistas de México. En este Congreso, celebrado en diciembre de 1936 en la Escuela Normal de Tenería, Estado de México, se estipuló que:

El Mexe, Hidalgo, fuese la sede oficial del Comité Ejecutivo Nacional de la FECSM. Esta condición trajo aparejado un subsidio mensual por parte de la SEP hasta la primera mitad de 1960 de acuerdo a la información consultada en los desclasificados del Centro de Investigación y Seguridad Nacional (CISEN). En este sentido los dirigentes estudiantiles no refieren carecer de recursos económicos para realizar sus labores de representación por el país (López, 2018, p. 76).

La pertenencia y dirigencia de una Federación, impregnaba de cierto poder al Comité Ejecutivo Estudiantil al que pertenecía el profesor, pero también a la base de estudiantes de una atmósfera de vitalidad en las decisiones que de cierta manera afectan la vida de todas las Normales aglutinadas en ese organismo político. Los discursos que preferían los dirigentes de la base eran de grandeza del normalismo 56 y única vía de emancipación de los explotados, a través de la conciencia de clase y el derribo de los explotadores que detentan el capital y los medios de producción, sólo a través de una posición revolucionaria desde las masas organizadas como agente de cambio. La violencia -en este sentido- resulta un marco adecuado para comprender cómo individuos y colectivos que presentan dificultades 
dentro de los marcos normativos que los constriñen y los direccionan en derroteros que se divorcian de sus deseos personales hacia otros, les son ajenos al ser concebidos por personas que se encuentran en posiciones de privilegio (Arteaga y Arzuaga, 20I7).

Si bien la institución peculiar se distinguía como criadero de políticos a partir de 1934 además de los motes de "escuelas del diablo" apátridas, viveros de líderes rojillos, bastiones comunistas (Ortíz y Camacho, 2017), practicantes de inmoralidades (Coll, 2015). "Estudiantes revoltosos, jóvenes holgazanes, instituciones que pertenecen al mundo de ayer" (Padilla, 2009, p. 85) y últimamente con el caso de los 43 estudiantes desaparecidos de la Escuela Normal Isidro Burgos de Ayotzinapa, Guerrero, se quedó también el mote de espacios donde el narcotráfico se ha infiltrado para abastecerse de elementos para la comercialización y distribución de drogas (Rojas, 20I7, p. 29). "Una vez más, las imágenes que emergen de los medios de comunicación del normalismo son de conflicto $y$, descontextualizadas, son muestra de la radical inconformidad que el gobierno utiliza para atacar o cerrarlas" (Padilla, 2009, p. 85),

Los dominadores utilizan la estigmatización; en este caso, las autoridades educativas lanzaron una campaña para desprestigiar a los estudiantes normalistas rurales por su rebeldía y desobediencia, y ejercieron presión mediante sanciones. También diseñaron una estrategia, mediante la reforma educativa para buscar una respuesta a las problemáticas existentes en el sistema normalista rural. (Flores, 2019, p. 208).

La lucha se relaciona ampliamente con la violencia abierta, que implica un concepto acusatorio y moralmente condenable en un mundo pacificado, donde el violento casi nunca tiene la razón. Además, que "Suelen ser pocos los medios de comunicación que cubren las luchas de los normalistas rurales y, cuando lo hacen, se recurre a una fórmula conocida: estudiantes revoltosos, jóvenes holgazanes, instituciones que pertenecen al mundo de ayer" (Padilla, 2009, p. 85). Karl Marx escribió que la violencia como partera de la historia asociada al cambio social entre la pugna de la lógica de los medios de luchas de clase. Aunque nunca definió con claridad la 
violencia, en su teoría juega un papel ambiguo y secundario. Desde su perspectiva es más bien un recurso contingente para la estructuración y el funcionamiento de la dominación y la eventual rebelión de las clases subalternas.

Otros teóricos que no parten de la lucha, sino de la teoría del equilibrio -como Max Weber- menciona que "La violencia se inserta en las relaciones sociales de lucha donde la acción social se orienta con el propósito de imponer la propia voluntad contra la resistencia de las otras partes" (Weber, I969, p.3I). La relación de tipo social es donde el sujeto construye y reconstruye su identidad con los otros, pues toda identidad es relacional y tiene necesariamente un carácter social donde puede considerarse un caso extremo y atípico, dirigido a la aniquilación del contrario, ya que lo predominante en un ordenamiento social es la competencia más o menos pacífica entre las partes implicadas. Weber se concentra en los procesos de legitimación del poder, donde aflora la violencia con coexistencia de procesos de crisis de la autoridad y su legitimidad. Sus características dependen del contexto en términos del proceso de penalización, que afecta no solo a la política sino también a la dimensión económica y de valores de moralidad humanamente entendida. La postura contestataria permite identificar similitud con el pensamiento que puede tildarse de poco alineado con el pensamiento de los que se encuentran en posiciones de poder "Sublime cuando se manifiesta en rebeldes de carácter prometeico que se niegan a someterse a la ley a costa de su propia exclusión y abyecta cuando deviene [...]" (Roudinesco, 2007, p. I4).

Las imágenes que los medios se han encargado de propagar entre la población no ha sido impedimento para que algunos estudiantes se entregaran casi religiosamente a la empresa de revolucionar el estado social de las cosas. Los más exitosos, aquellos que demostraban un conjunto de disposiciones ${ }^{6}$ contextuales hechas cuerpo (Paladino, 20I2), desarrolladas por su cercanía a la vida normalista, proclives a vivir dentro de un nicho que hace política con sus altos y sus bemoles; con fervor casi indecible, que recordaba a los monjes entregados a la lectura, que teorizaba sus discursos y la realización práctica de 
actividades que ayudaban a la generación de condiciones de solidaridad, por lo menos en lo que la apariencia permite entrever.

Para llegar a un grado de convicción que permita la operación efectiva de los alumnos, requería en ese momento histórico de una base teórica que permitiera ver la realidad de un modo que visibilizara un tipo de injusticia ejercida sobre los sectores marginados, de donde provenían los estudiantes que poblaban las Normales rurales de México. Los jóvenes sufrían de la exclusión de los bienes económicos y culturales principalmente. La identificación precisa que ellos, y en especial el profesor Gordiano realizaron, brindaba el cimiento de toda la construcción que justificó constantemente la lucha de los alumnos.

El grupo al que se le encargaba la concientización recibía el nombre de Comité de Orientación Política e Ideológica (COPI), una de las áreas más activas en condiciones regulares o de movimiento. $\mathrm{Su}$ labor: la concienciación de los estudiantes sobre la explotación de los oprimidos, como una acción que esfuerza la experiencia para ser simbolizada, sin que quede deformada a causa de los mecanismos de protección propios de cada sujeto, para que pueda -llegando el casoser accesible a la conciencia (Artiles, 1994).

La mirada del otro en una posición privilegiada y la toma de conciencia sobre la condición de cada alumno, como perteneciente a la clase explotada, por medio del análisis de la teoría Marxista en círculos de estudio, era coordinada por los compañeros con mayor experiencia en los asuntos de izquierda, que en resumen postula:

[...] que el estado de bienestar no ha reemplazado la explotación de los asalariados, y que si bien ha suministrado servicios y transferencias monetarias que han beneficiado a los pobres y a la clase trabajadora, también sirve para sostener el capitalismo a largo plazo, ya que fortalece las bases de funcionamiento de la economía de mercado (legitimación, reproducción de la dominación y reproducción del capital). Para ellos la desigualdad tiene su origen en la división de la sociedad en clases, y la apropiación del producto social de unas por las otras. Defienden que las necesidades 
humanas son un asunto colectivo y que, tanto en su definición como en su satisfacción, deben intervenir los ciudadanos mediante una democracia más directa y participativa en las instituciones públicas" (Adelantado, 2000, p. 6).

En tiempos de movimiento los integrantes del COPI se encargaban de difuminar con más fuerza la ideología marxista y el pensamiento de Che Guevara y Lennin entre los estudiantes (Civera, 20I5). Bastaba cualquier indicio del Estado como una muestra de la opresión y el desinterés a las demandas que consideraban justas del pueblo oprimido. La propagación de la mirada que lograban construir en ese momento histórico se extendía al exterior de la Normal, a través de papeles en media carta que contenía -de manera concreta- su visión y las demandas al gobierno en turno y diversas consignas que animaban al pueblo en general a develar el velo que les cubría los ojos y les mantenía atados al yugo de esclavitud impuesto por la clase que detentaba los bienes de producción y el capital.

El profesor Gordiano Vite, había consumido los insumos teóricos necesarios para tener claridad de su origen. Esta situación marcó el norte de su proceder como estudiante en la Normal, donde las actividades comenzaban a las cinco de la mañana con clases de educación física a cargo del profesor Salomón Nazar, seguida por el desayuno a las ocho de la mañana, y clases de asignatura de donde sobresale las cuatro horas dedicadas al dominio de las técnicas de enseñanza impartidas por el profesor José Santos Valdez García de León, ${ }^{7}$ uno de los educadores más ilustres del estado de Coahuila y que socialmente se recuerda con una estatua a la entrada principal de la ciudad capital de su estado natal, un busto en el Instituto de Estudios Superiores de Educación Normal en Lerdo, Durango, y otro en la Plazuela Juárez del mismo lugar (Rodríguez, s/f).

La orientación institucional de los aprendizajes, tenían la intención de preparar a sus alumnos para ser exitosos en la vida propia del campo, para lo cual impregnaban de conocimientos prácticos útiles en la inmersión a su vida activa. Las asignaturas que tenían este cariz eran la de agricultura y ganadería, que se estudiaban en contacto 
directo con el uso del azadón, así como la ordeña y crianza del ganado. Las condiciones que hacían posible la educación agrícola y ganadera se anclaban en el riego de aguas negras que hacían fértil la tierra todo el año, además de la maquinaria necesaria para su labranza:

Bueno la central agrícola propiamente llevaba la tendencia a formar ingenieros, es otro rubro este, acá simplemente capacitarnos para poder hacer frente a los problemas de las comunidades rurales de la educación rural y la agrícola pues si ya era específicamente para formar ingenieros que fueran ya a realizar otro tipo de actividades más específicas (Vite, 20I4, p. 2).

$\mathrm{Su}$ formación transcurre apegada a las actividades juveniles propias de su edad, en un marco que da dirección a las pautas permitidas en su época. Las tardes de bohemia con guitarra en mano y los eventuales traslados al municipio de Francisco I. Madero a pie, por los dos kilómetros que separan a la escuela, se convirtieron en actividades habituales. Esta práctica dejaba entrever al ser humano necesitado de convivencia y apego entre los de su misma edad. Esta actividad la denominaba como Beatería o Ratitos de bohemia, lo que lo lleva a proferir con gran seguridad que: "la vida de estudiante es la más bonita" (Vite, 20I5, p. 5).

\section{Su incorporación al magisterio hidalguense desde 1956 hasta su muerte en} el mes de enero de 2018

A su egreso tras estar escolarizado de 1949 a I956, el siguiente paso fue su incorporación como maestro al servicio del Estado. El primer lugar al que se le asigna se encontraba en San Luis Potosí. Su cercanía con el profesor Alfredo Arciniega Monroy, sirve para que le asigne al estado de Hidalgo, específicamente al municipio de Calnali. Su llegada se da en medio de un conflicto por un infortunado accidente de un niño que cayó en un pozo que se usaba para la extracción de agua para la escuela primaria. La encomienda: "Vas a abrir esa escuela" la recibe de su tío Profr. Jesús Vite Mercado ${ }^{8}$ entonces Director de Educación en el Estado de Hidalgo: 
[...] y ni modo, ahí me inicié atendiendo primero y segundo grados [...] fue una tarea convencer a los padres de familia de que otra vez volvieran a enviar a sus hijos allá a la escuela "I8 de marzo" y me di a la tarea de interesar a los padres de familia, las autoridades para construir una escuela, porque era una [...] galera con rajas y todo eso de lodo completamente antihigiénica porque se colaba el agua y todo eso el frío [...] yo estuve ahí dos años y logré la construcción de la escuela y ahora tienen una escuela pues bien dotada (Vite, 20I4, p.3).

Esta manifestación es signo de la cercanía o la distancia es un fenómeno de profundas raíces sociales en el manejo con los que se encuentran en posiciones de mayor ventaja: "En suma, es posible servirse de las distancias objetivas de manera de tener las ventajas de la proximidad" (Bourdieu, 1987, p. 13I) y las ventajas que la distancia puede significar con algunos sujetos sociales. La cercanía del profesor, manifiesta un tipo de amistad del tipo instrumental que se desarrolla cuando uno de los miembros es claramente superior al otro en capacidad de generar bienes simbólicos (Adler, 200I).

A pesar de que sus planes no eran regresar al lugar del que 7 años atrás había salido con 23 horas de camino, no pudo desestimar la instrucción y permanece dos años en la escuela primaria "I8 de marzo" del Barrio Nuevo de la cabecera municipal de Calnali, tras dejar una organización más efectiva y las instalaciones que superan a la galera que había encontrado a su llegada.

La siguiente escuela a la que fue asignado en 1958, por el propio inspector escolar, fue la primaria "Cristóbal Contreras" ubicada en la cabecera municipal. Ahí atiende al sexto grado por casi 20 años. La forma de trabajo docente en ese entonces no se parece al actual. El 62 horario se caracterizaba por su amplitud y discontinuidad: de 9:00I4:00 horas se priorizaba la enseñanza académica y de 15:00-I7:00 horas los talleres de tejido de bejuco, costura, bordado de mapas, canastas con alambre, entre otras manualidades.

De las diecinueve a las veintidós horas se priorizaba la lectura: empecé trabajando horario discontinuo, de 9:00 a 2:00 y luego de 
3:00 a 5:00 y en la noche de 7:00 a I0:00 atendía yo una sala de lectura, alfabetizaba yo [...] me dieron un aparato de sonido, música y todo, pues ponía yo mis, conseguí una planta de luz pues porque no había electricidad" (Vite, 2015, p. 4).

Vite (20I8) menciona que, en esa sala de lectura, enseñó a leer a un jovencito con síndrome de Down. En su municipio se hizo director y posteriormente supervisor, por su sistematicidad en la observancia de la técnica y su capacidad organizacional de los centros en los que le tocó desempeñarse y la cercanía con los sujetos sociales que podrían proporcionarlos:

El logro de los ascensos se encuentra en función de las buenas relaciones que se tengan con quienes ocupan puestos de mandos. Saber que el trayecto de ascensos no es lineal y que son muchos los factores que inciden en él, principalmente los de orden político (Montiel, 2005, p. II5).

En su función como supervisor, dividió la zona en cuatro sectores para implementar la competitividad entre las escuelas en dos ámbitos específicos: el físico y manual. El primero en los encuentros deportivos y el segundo en los eventos culturales. Bajo esa dinámica se conduce hasta 1980, cuando es comisionado a la ciudad de Pachuca por el entonces Director Federal de Educación, profesor Alberto Jiménez Montes, para estar al frente del Plan para Mejorar la Calidad de la Educación (PLANCAED), donde desempeñó su función recorriendo todo el estado y atendiendo las demandas de los familiares, autoridades educativas y alumnos.

Al término de su comisión le asignaron como supervisor general del sector No. 9, con sede en la ciudad de Sahagún, municipio de Tepeapulco, de donde recuerda como detalle al profesor José Sierra Badillo, que solo faltaba para ir al carnaval de su tierra en el municipio de Eloxochitlán, dentro del mismo estado. Con él compartía el origen del Normalismo Rural y la FECSM. El primero por la Normal Rural "Lázaro Cárdenas del Río" de Tenería, Municipio de Tenancingo, Estado de México y el segundo como se 
viene repitiendo de la Normal Rural "Luis Villarreal” del Mexe, en el estado de Hidalgo.

El compromiso en la tarea educativa fue una constante en la vida institucional del profesor Gordiano Vite Ortega. Su discurso transita por la preparación constante para realizar su labor de la mejor manera y su avidez por el conocimiento que acrecentaba con las posibilidades de la época "Mi padre tomó varios cursos por correspondencia, para el desarrollo de esas actividades, entre otros, tejido mediante bastidores y electrónica" (Vite, 20I8).

Su proceder lo aprendió de su Alma Mater a través de la profesora Delfina Hernández Santander, el profesor Salomón Nazar y el director José Santos Valdés quien, con su carácter enérgico, le templó para las adversidades. Convencido de que la realidad es un constructo social que puede comprenderse desde otras perspectivas, prosiguió sus estudios superiores en la Universidad Pedagógica Nacional con sede en Pachuca, de I975 a I979, egresando como Licenciado en Educación Primaria en la primera generación de esta institución (Vite, 20I8). De allí se desprende que lo nombraran a menudo como "Profesor y licenciado". Otro nivel de estudio alcanzado a nivel de licenciatura fue en la carrera de Derecho, que cursa de I988 a 1992 en la Universidad Autónoma del Estado de Hidalgo (UAEH).

$\mathrm{Su}$ proceder institucional y su apego al capital cultural como "un principio de diferenciación casi tan poderoso como el capital económico" (Bourdieu, 20I2, p. 69), hacen de él un sujeto peculiar, de notoriedad académica como figura.

Típica del capital simbólico, que sólo existe a través de la reputación, es decir, de la representación que de ellos se formen los demás, en la medida que se comparten un conjunto de creencias apropiadas para hacerla percibir y valorar unas propiedades y unos comportamientos determinados como honorables (Bourdieu, I994, p. 108). 
En las empresas en que se enroló además de lo narrado, está el de haber obtenido el máximo grado dentro de la Masonería en la entidad hidalguense y distinguido con el cargo de "Muy respetable gran Maestro de la Gran Logia del Estado de Hidalgo". Su capital social y cultural le proporcionaron honorabilidad, respetabilidad y confianza de sus superiores y compañeros maestros.

\section{Conclusiones}

La partida del profesor Gordiano Vite Ortega se da el 27 de enero de 20I8, con 62 años de trabajo ininterrumpidos al servicio de la Secretaría de Educación Pública de Hidalgo (SEPH). Su paso por la educación marcó varias generaciones que le recuerdan por su carisma en el trato y la exactitud de su palabra, acorde al origen que siempre llevó consigo y que lo puso a salvo de los regresos subrepticios de los recuerdos coagulados, actos repetitivos, momentos rituales o guiones fantasmáticos (Remedi, 2004).

El título de profesor no le bastó en el infinito mundo del conocimiento, tomando la decisión enmarcada en la oferta académica del momento para acrecentar su capital cultural como "principio de diferenciación casi tan poderosa como el capital económico" (Bourdieu, 20I2, p. 69). La idoneidad en su función la remitió con la frase de "Hago lo que me toca" como muestra de su entrega en la tarea que complementa con sus estudios universitarios en educación, derecho y en la multitud de cursos a distancia y presenciales.

$\mathrm{Su}$ vida es muestra de un proceder apegado al conocimiento de la institución "partiendo de la temporalidad del ser ahí que cuenta con el tiempo" (Heidegger, I95I, p. 444). El tiempo del sujeto dentro de la institución dedicada a la escolaridad como un bien público, fue vivido por él con un sentido sincrónico a sus demandas y procederes, mientras su tiempo biológico transcurrió dentro del tiempo institucional como "un espacio de posiciones y un conjunto de trayectorias, que unidos determinan algunas de las relaciones que se 
dan entre los individuos y algunas de las oportunidades que tienen a su disposición" (Thompson, 2006, p. 4IO).

Sumergirse en el análisis de su discurso, permitió descubrir los sentido de lo que decía en cuanto sujeto que trascendió dentro de la educación primero, por la incorporación de títulos, con apego a una antigua representación donde las credenciales no escapan a las devaluaciones y segundo, al funcionamiento de los mismos que se respaldan por sus años de servicio, aunado a un tercer factor que tiene su base en su cúmulo de relaciones humanas con funcionarios clave que también ocuparon puestos donde se toman las decisiones laborales importantes.

\section{Referencias}

Adler, L. (200I). Redes sociales, cultura y poder. Ensayos de antropología latinoamericana. México: Porrúa.

Adelantado, J. (200o). Cambios en el estado de bienestar. Políticas sociales y desigualdades en España. Barcelona: Icaria.

Adelas. (20I5). Historia de Adelas. Recuperado de: http://adelas.com.mx/historia.php\#: :text=La\%2Oempresa\%2 C\%20Transportes\%20Autobuses\%20de,de\%2oDon\%2oRicar do\%2oZepahua\%2oGuti\%C3\%A9rrez.\&text=El\%2onegocio\% 2odel\%2otransporte\%2C\%2oen,carga\%2opor\%2otoda\%2ola \%2oregi\%C3\%B3n.

Arteaga, N., y Arzuaga, J. (2017). Sociología de la violencia. México: FLACSO.

Artiles, M. (1994). Psicopatología: Personalidad normal y anormal. En M. Artiles, Psicología Humanista: Aportes y orientaciones (pp. 87I07). Buenos Aires: Docencia.

Bourdieu, P. (1987). Cosas Dichas. México: Gedisa.

Bourdieu, P. (1994). Razones Prácticas. Sobre la teoría de la Acción. Barcelona: ANAGRAMA.

Bourdieu, P. (20II). Las estrategias de la reproducción social. Buenos Aires. Argentina: Siglo XXI Editora Iberoamericana 
Bourdieu, P. (1998). La distinción, Criterios y bases sociales del gusto. Madrid: Grupo Santillana de Ediciones

Bourdieu, P. (2012). Capital Cultural, Escuela y espacio social. México: Siglo XXI.

Civera, A. (2015). Normales Rurales. Historia mínima del olvido. Recuperado de: https://www.nexos.com.mx/?p=24304

Coll, T. (2015). Las Normales Rurales: noventa años de lucha y resistencia. El Cotidiano, (I89), 83-94. Recuperado de: https://www.redalyc.org/articulo.oa?id=325338190I2.

Cordero, E. (I966). Historia compendiada del estado de Puebla. Puebla: Bohemia Poblana.

Cortés, F., y Hernández, T. (2009). La educación Rural en México y la Escuela del Mexe han Cumplido. México: s/e.

Duby, L. (1998). Diálogos sobre la historia. Madrid: Alianzaeau.

Flores, Y. (2019). Escuelas Normales Rurales en México: movimiento estudiantil y guerrilla. Iztapalapa, Revista de Ciencias Sociales y Humanidades, 2005-226. Bourdieu (2002).

Foucault, M. (2000). Defender la sociedad. México: FCE.

Foucault, M. (2007). Historia de la sexualidad I. México: FCE.

Fukuyama, F. (1999). La gran ruptura. España: Atlántida .

Heidegger, M. (I95I). El ser y el tiempo. México: FCE.

Hernández (200I). De Santo Roa a los Frailes. México: Impresiones siglo XXI.

López Macedonio, M. N. (20I8). Los estudiantes Normalistas Rurales y el Partido Comunista Mexicano en la historia política del siglo XX. Anuario Mexicano de Historia de la Educación, I(2), 6784 .

Martínez, M. (2015). La revolución entra a la escuela. Recuerdos, imágenes y vivencias de la educación socialista en México. Revista Mexicana de Historia de la Educación, 3(5), 22-46.

Montiel, M. (2005). La supervisión en el sistema de educación básica en el estado de Hidalgo: Eufemización del ejercicio de poder y su relación con el género. México: UPN. 
Moreno, A. (2018). Normal Rural Luis Villarreal. Tensiones, negociaciones y conflictos en la primera generación de Educación Especial en el estado de Hidalgo [Tesis no publicada]. Hidalgo, México.

Ortíz, S., y Camacho, S. (20I7). El normalismo rural mexicano y la "conjura comunista" de los años sesenta. La experiencia estudiantil de Cañada Honda, Aguascalientes. Revista Mexicana de Historia de la Educación, 5(I0), 245-268. DOI: https://doi.org/I0.2935I/rmhe.v5iIo.II6.

Paladino, M. (20I2). De la hermenéutica a la sociología de la ciencia. En M. E. Jarquín, Las ciencias sociales en la actualidad (pp. 22-29). México: UNAM.

Padilla, T. (2009). Las normales rurales: Historia y proyecto de nación. El Cotidiano, (I54), 85-93.

Portelli, A. (2016). Historias Orales. Narración, Imaginación y diálogo. España: Prehistoria.

Remedi, E. (2004). Instituciones educativas. Sujetos, historias e Identidades. México: Plaza y Valdés.

Rizo, M. (2009). Un diálogo posible. Sociedad y cultura en la obra de Alfred Scutz y Pierre Bourdieu. En E. Sandoval, Cultura y poder (pp. 345-39I). México: UACM.

Rodríguez, V. (s/f). Profr. José Santos Valdés García de León. Educador, escritor y luchador social. Coahuila, México: Secretaría de Educación del Estado de Coahuila.

Rojas, J. (20I7). El movimiento estudiantil de la Escuela Normal Rural de Atequiza. Un análisis de sus prácticas sociales y políticas, I988-20I5. Intersticios sociales, (I3), I-33.

Roudinesco, E. (2007). Nuestro lado Obscuro. Barcelona: Anagrama.

Thompson, J. (2006). Ideología y cultura moderna. México: Universidad Autónoma Metropolitana.

Tuirán, R., y Quintanilla, S. (2002). La educación en México durante el periodo de Lázaro Cárdenas, 1934-1940. En L. E. Galván, Diccionario de historia de la educación en México. México: UNAM-CIESAS-CONACYT.

Vite M. (20I0). La formación docente en el marco de la cultura institucional de la Escuela Normal Rural "Luis Villarreal", 
Vite, G. (Abril de 20I4). Experiencia vivida. (A. Moreno, Entrevistador).

Vite, G. (Abril de 20I5). Memorias. (A. Moreno, Entrevistador).

Vite, M. (2018, I2 de mayo). Entrevista realizada por Alejandro Moreno Lozano. Hidalgo, México.

Voloshinov, V. (1976). El signo ideológico y la filosofía del lenguaje. Argentina: Ediciones Nueva Visión SAIC.

Weber, M. (1969). Economía y sociedad. México: Fondo de Cultura Económica.

Zimbardo, P. (2007). El efecto Lucifer. El nacimiento de la maldad. Barcelona, España: ESPASA.

\section{Notas}

${ }^{\text {I }}$ La empresa, Transportes Autobuses de la Sierra S. A. de C. V., nace en la Sierra de Zongolica, Veracruz, en el año de 1945, bajo la responsabilidad de Don Ricardo Zepahua Gutiérrez. Conforme fue creciendo y modernizandose. Los métodos se volvieron más eficaces cuando el transporte, que era tirado por caballos, fue motorizado a partir de 1905. En 1943 empezó a llegar a los lugares más recónditos de México, entre ellos Zongolica, ya que los caminos eran de terracería y muy estrechos. Para el año de 1945, se logró obtener seis permisos para brindar el servicio de transporte público, los cuales iban acompañados de sus respectivas unidades para dar la prestación (Adelas, 2015).

${ }^{2}$ La decisión del profesor no se toma en el vacío, tenía el beneficio de un hermano en el segundo año de Normal, y a través de su experiencia adquirió un mejor entendimiento de las dinámicas institucionales específicas de ese momento, además de un lugar seguro para pernoctar y el acompañamiento en las decisiones en cuanto a concretar su proyecto de estudios profesionales, en lo que parecía ser la única opción viable para los provenientes de su clase social: "con mi madre éramos nada más dos, el que ya estaba acá y yo, entons mi madre me dijo, no... tú te vas a estudiar, y sí, con el apoyo de mi hermano que ya estaba acá, logré ingresar y toda la cosa" (Vite, 20I4, p. 7).

${ }^{3}$ En el Diario Oficial de la Federación se consigna que el 3 de octubre de 1925, el gobierno de la República realizó la compra de la Hacienda de San Antonio El Mexe, propiedad de la Familia Requena (Vite, 20Io). En ese mismo año se fundó también la Central Agrícola de La Huerta, Michoacán (Hernández, 200I). El primer director del plantel fue el ingeniero Policarpo Garza, egresado de la Allen Academmy de Bryan, Texas y del Iowa College de Ames, State. 
4 “Don Plutarco Elías Calles en su juventud fue maestro Rural y convivió con campesino, por lo que, conocedor además de la historia Patria no le eran ajenos los problemas del México Rural" (Hernández, 200I, p. 64).

${ }^{5}$ Durante el gobierno de Lázaro Cárdenas (1934-1940), se buscó democratizar el acceso a la educación, se impulsó el combate al analfabetismo, y se apoyó la educación rural e indígena. Además, en este periodo se crearon escuelas vinculadas a centros de producción y se alentó la enseñanza técnica. En 1934, se modificó el Artículo $3^{\circ}$ constitucional vigente desde 19I7para establecer el carácter socialista de la educación. La postura fundamental: "La Educación que imparta el Estado será socialista y, además de excluir toda doctrina religiosa, combatirá el fanatismo y los prejuicios, para lo cual la escuela organizará sus enseñanzas y actividades en forma que permita crear en la juventud un concepto racional y exacto del universo y de la vida social" (Cordero, I966, p. I20) Esta polémica reforma también amplió las facultades del gobierno federal para controlar los distintos niveles del sistema educativo y vigilar el funcionamiento de las escuelas particulares (Tuirán y Quintanilla, 2002).

${ }^{6}$ El habitus "Designa al conjunto de disposiciones de los agentes en que la práctica se convierte en principios generadores de nuevas prácticas" (Bourdieu, 20II, p. I2). "El habitus se define como un sistema de posiciones durables y transferibles -estructuras estructuradaspredispuestas a funcionar como estructuras estructurantes- que integran todas las experiencias pasadas y funciona en cada momento como matriz estructurante de las percepciones, las apreciaciones, las acciones de los agentes, coyunturas o acontecimientos y que él contribuye a producir" (Bourdieu, 2002, p. 52).

7 "Nació en el Rancho Camargo que era una pequeña propiedad perteneciente a uno de los lotes del histórico Cuadro de Matamoros repartido por el presidente Benito Juárez en I864, hoy el Rancho Camargo sigue llevando este nombre y colinda con el Ejido Flor de Mayo que se encuentra a escaso medio kilómetro y con la pequeña propiedad El Edén que pertenece al Sr. Guadalupe Ramírez, sobrino segundo del Profesor. José Santos Valdez" (Rodríguez, s/f, p. 4).

${ }^{8}$ Su cercanía por parentela o por amistad puede leerse como un capital social de "Relaciones mundanas que pueden, llegando el caso, proporcionar apoyos útiles, capital de honorabilidad y de respetabilidad que a menudo es indispensable para atraerse o asegurarse la confianza de la buena sociedad y, con ello su clientela, y que puede convertirse, por ejemplo, en una carrera política" (Bourdieu, I998, p. II8).

Este artículo se publica bajo una licencia de Creative Commons Reconocimiento-NoComercial 4.0 Internacional, y puede ser usados gratuitamente para fines no comerciales, dando los créditos a los autores y a la revista. 